\title{
ОПРЕДЕЛЯНЕ НА ТЕЖЕСТТА НА ИЗГАРЯНЕТО И ПРИЧИНЕНАТА ОТ НЕГО ТЕЛЕСНА ПОВРЕДА: ВАUХ СРЕЩУ АIS
}

Е. Каичева

\section{DETERMINATION THE SEVERITY OF THERMAL INJURY AND BODILY HARM USING R-BAUX AND AIS}

\author{
E. Kaisheva
}

Рез юме. Въпреки постоянното развитие на медицината, термичната травма и нейните последици продължават да са сериозен сочиилен, медицински и съдебномедицински проблем в световен мащаб, наложил създаването и използването на точен метод за определяне на тежестта на термичното увреждане и прогнозиране на изхода от него. Целта на проучването е да оценим точността на R-Baux и AIS системите за прогнозиране на риска от летален изход при термична травма чрез сравняване на изчисления по тях риск с действително реализирания, както и да разгледаме възможността за определяне на тежестта на причинената телесна повреда. Проучени са всички случаи с изгаряне, постъпили в Клиниката по термична травма, пластично-възстановителна и естетична хирургия при „МБАЛ - Варна“ за пет годишен период (2011-2015 г.). Получените резултати дават възможност да се оформят групи съобразно тежестта на травмата според стойността на AIS и R-Baих и реализираната опасност за живота. При стойности на AIS 1 леталитетът е под 0,1\%. При стойности 2, 3 и 4 леталитетът е между 0,6 и 15\%, а при стойности 5 и 6 той е между 60 и $90 \%$. За другата разглеждана система - R-Bаих, зависимостта е: при стойности, по-малки от 20 - няма риск за живота, между 21 и 120 - рискът е до 44\%, а при стойности над 120 е повече от 90\%. Установи се, че двете системи са подходящи за определяне на риска от смъртен изход след термична травма и посочените ицифрови стойности могат да се използват като ориентир от съдебните медици при квалифициране на телесната повреда вследствие на изгаряне и за определяне на степента, в която е застрашен животът на пострадалия.

S u m m a ry. Despite constant progress in medicine, thermal injuries and their consequences continue to be a serious social, medical and forensic problem worldwide, requiring the creation and use of a precise method for determining the severity of thermal injury and predicting its outcome. The aim of our study was to confirm the accuracy of the R-Baux and AIS systems in predicting the risk of fatal thermal injury by comparing the calculated values with the actual reported as well as to examine the possibility of determining the cause of bodily injury. All burn cases for the 5 year period (2011-2015) admitted to the Clinic of Thermal Traumas and Plastic-Restorative and Aesthetic Surgery at the Military Hospital - Varna were studied. The obtained results allowed us to form three groups according to the AIS and R-Baux values, and the reported in the clinic percentage of fatal cases. At AIS 1, the mortality is below 0.1\%. At 2, 3 and 4 it is between 0.6 and $15 \%$ and at values 5 and 6 it is between 60 and 90\%. For the other system, R-Baux, we have the following dependency: for values less than 20 - there is no threat to life, between 21 and 120 - the risk is up to $44 \%$ and at values above 120, the risk is higher than $90 \%$. It was confirmed that the two systems are suitable for calculating the risk of death after thermal injury and that the obtained numerical values could be used as a reference by the forensic physicians in the classification of bodily injury due to burns, according to the extent to which the life of the patient is threatened.

Key words: thermal injury, scoring systems, trauma assessment, bodily injury

\section{Въведение}

Термичната травма и нейните последици и днес продължават да са сериозен проблем в световен мащаб. Въпреки разликата в социалните, икономическите, здравните и др. условия в различните страни, изгарянията навсякъде са съпроводени с различни по степен нарушения във функциите на засегнатите области от тялото, от леки до инвалидизиране и налагат скъпоструващи, специализирани медицински грижи и лечение за продължителен период от време [2, 7, $12,21]$. Използването на точен метод за определяне на тежестта на термичното увреждане и прогнозиране на изхода от него би подпомогнало медицинските специалисти, пострадалите и техните семейства при вземане на решения относно обема и вида на медицинските грижи за тези пациенти, както и съдебните медици при уточняване на вида на причинената телесна повреда $[5,23,26]$. Това е наложило създаването и използването на различни точкови прогностични системи и формули за определяне на тежестта на термичната травма и изхода от нея. Колкото една система или формула е по-точна, толкова е по-полезна. Класически пример за изчисляване на процента вероятност за смъртен изход е сборът от възрастта на пациента и площта от общата телесна повърхност, засегната от изгарянето, представена в проценти - метод на Baux. [11, 15, 20, 26-29, 31]. При многобройни проучвания и наблюдения на пациенти с термична травма е доказано, че значение за изхода от нея има и наличието на инхалационни увреждания. Това е наложило ревизиране на системата за предвиждане на вероятността от смъртен изход като се отчита и влиянието на инхалационните увреждания. През 2010 г. Osler и съавт. предлагат нова формула [19]:

R-Baux score = площта от общата телесна повърхност, засегната от изгарянето, представена в проценти + възрастта на пострадалия + (17xR)

$\mathrm{R}$ e 0 или 1 в зависимост от това дали пострадалият няма или има инхалационно увреждане.

Друга система, проучена за приложение при предвиждане на тежестта на увреждането от изгаряне и вероятността за летален изход от него, е Abbreviated Injury Scale (AIS - съкратена ска̀ла на травмите) [10]. Тя представлява специфична точкова система за класификация на травмите въ3 основа на анатомично описание на тъканните увреждания. Тежестта на травмата се определя чрез едноцифрена оценка по рангова ска̀ла от 1 до 6 на базата на площта от телесната повърхност, засегната от изгарянето, степента на изгарянето и възрастта на пострадалия. Установена е отлична корелация между тежестта на оценката AIS и преживяемостта: при оценка 1 до 3 преживяемостта варира от 99.3\% до 96.5\%. При оценка 4 средната преживяемост е 85.4\%, при оценка $5-60.4 \%$, (което съответно означава, че рискът за смърт е $39.6 \%$ ), а при оценка 6 преживяемостта е $21 \%$.

Целта на настоящото проучване е чрез получените резултати да се определи точността на R-Baux и AIS системите 
при прогнозиране на риска от летален изход при термична травма чрез сравняване на изчисления по тях риск с действително реализирания, както и да се определят цифрови показатели по двете системи, изпълващи определен медико-биологичен признак относно опасност за живота, позволяващо класифициране на увреждането от изгаряне като съответна степен телесна повреда.

\section{Материал и методи}

В настоящото проучване се използват AIS 2008 и RBaux (ревизираната система, при която се взема под внимание и наличието на инхалационно увреждане).

Данните, необходими за изследването, са изведени от медицинските документи на пациентите с изгаряне, постъпили в Клиника по термична травма, пластично-възстановителна и естетична хирургия (КТТПВЕХ) при „МБАЛ - Варна“ за пет-годишен период (01.01.2011-31.12.2015 г.)/. Отчетени са стойностите на нужните за изчисляване на RBaux и AIS показателите фактори - възраст на пострадалия, процент засегната от изгарянето площ от телесната повърхност, степен на изгарянето, наличие или не на инхалационно увреждане.

Определянето на процента на засегнатата от изгарянето площ е извършено по правилото на девятките (правило на Walles), а степента на изгарянето - по общоприетата класификация - I, II A, II B, III ст.

Наличието на инхалационно увреждане е преценено на база посоченото в медицинските документи - анамнеза, клинични симптоми и промени в кръвно-газовия анализ.

Всички разглеждани случаи са разделени на две групи според изхода от термичната травма: починали и оцелели.

Изчислени са R-Baux и AIS показателите за всеки един случай.

Използван е регресионен анализ за определяне на влиянието на всеки от разгледаните показатели върху смъртността и връзката между реалната смъртност и предвидената възможност за настъпването ѝ на базата на посочените показатели. Количествените (цифровите) данни са обработени чрез стандартни статистически методи, обобщени и представени в Таблици 1-3.

\section{Резултати}

Общо 2036 пациента с изгаряне са постьпили за лечение в клиниката през разглеждания пет годишен период. Средната възраст е 40.1 г., като минималната е 1 месец, а максималната е 93 г. Тази стойност при починалите и при оцелелите пациенти е съответно 62.5 и 39.3 г.

От постьпилите за лечение, 74 са починали. Общата смъртност е $3.6 \%$. Смъртта е настьпила още в острата фаза (до 3 дни след инцидента) в 21 от случаите, в 28 - между 4 и 10 ден, в 16 - между 11 и 22 ден и в 9 - повече от 22 дни след изгарянето.

Средната площ, засегната от изгаряне, е $8.33 \%$ от общата телесна повърхност, с минимум 1\% и максимум $100 \%$, като средната изгоряла площ при починалите е $52.3 \%$, а при оцелелите $6.67 \%$.

Всички пациенти с II А степен изгаряне са оцелели и изписани от отделението. От тези с II В ст. починалите са $0.34 \%$, а с трета $-8.75 \%$.

Установените стойности на R-Вaux при летален изход са от 24.4 до 177, средно 121.8. При пациентите, преживели травмата и изписани от отделението, стойностите на тези показатели са съответно 1; 143 и 47.80. Таблица 1

Отчетени по AIS, посочените показатели са със стойности съответно при пациентите с летален изход: минимум 1, максимум 6, средно 4.6 (4-5). При оцелелите пациенти: минимум 1, максимим 6, средно 1.4 (1-2). Таблица 2
Таблица 1. Стойност на R-Ваих показателя и съответния прочент реално отчетена смъртност

\begin{tabular}{|c|c|c|c|c|c|c|c|c|c|}
\hline $\begin{array}{c}\text { Стойност } \\
\text { на R-Ваих } \\
\text { показателя }\end{array}$ & $<20$ & $\begin{array}{c}21- \\
90\end{array}$ & $\begin{array}{c}91- \\
100\end{array}$ & $\begin{array}{c}101- \\
110\end{array}$ & $\begin{array}{c}111- \\
120\end{array}$ & $\begin{array}{c}121- \\
130\end{array}$ & $\begin{array}{c}131- \\
140\end{array}$ & $\begin{array}{c}141- \\
150\end{array}$ & $\begin{array}{c}151- \\
177\end{array}$ \\
\hline $\begin{array}{c}\% \text { смърт- } \\
\text { ност }\end{array}$ & 0 & $\leq 1$ & 13.11 & 18.92 & 44.44 & 88.89 & 93.33 & 90 & 100 \\
\hline
\end{tabular}

Таблица 2. Стойност на AIS показателя и съответните прогностична опасност за живота и процент реално отчетена смъртност

\begin{tabular}{|c|c|c|}
\hline $\begin{array}{c}\text { Cтойност на } \\
\text { AIS показа- } \\
\text { теля }\end{array}$ & Прогностична опасност за живота & $\begin{array}{c}\% \text { смър- } \\
\text { тност }\end{array}$ \\
\hline 1 & незначителна & 0.07 \\
\hline 2 & умерена & 0.60 \\
\hline 3 & сериозна & 6.00 \\
\hline 4 & тежка & 14.50 \\
\hline 5 & критична & 62.90 \\
\hline 6 & максимална (понастоящем нелечима) & 87.50 \\
\hline
\end{tabular}

\section{ОбсъжАане}

Въпреки че през последните десетилетия се съобщава за непрекъснато намаляване на смъртността, вследствие изгаряне, такава все още се отчита. При настоящото проучване тя е $3.6 \%$, сходно на отразеното при други подобни изследвания [23, 24]. Olaitan и съавт. [18] отчитат значително поголяма смъртност - $20 \%$, което най-вероятно се дължи на факта, че в тяхното проучване са включени само случаи на тежки изгаряния.

Доказана е вече ролята на редица фактори, повишаващи вероятността от летален изход от термичната травма. Сред тях са: площ на изгарянето (\% от общата телесна повърхност), степен (дълбочина на изгарянето), възраст на пострадалия, наличие на инхалационно увреждане и др. [14, 23, 31].

Средната, засегната от изгарянето площ, уточнена при настоящото проучване, е $8.33 \%$. Подобни данни са отчетени и от други изследователи $[23,28]$. Стойността на този показател, установена от нас, при леталните случаи е $52.3 \%$, а при оцелелите $-6.7 \%$. Резултатите категорично показват, че по-голямата площ на изгарянето, спрямо общата телесна повърхност, е свързана с по-голям риск от летален изход $[4,5,11,14,15,23,26]$.

Степента на изгарянето също има значение за определяне на неговата тежест и изход. При наличие на III ст., дори при по-малка засегната площ, увреждането е по-тежко и с по-лоши последствия [3, 13, 17].

Друг важен за прогнозирането на леталния изход показател е възрастта на пострадалия. Колкото е по-напреднала възрастта, толкова е по-голяма вероятността от смъртен изход. При възрастните пациенти прогнозата е по-тежка поради наличието при тях на редица придружаващи заболявания $[4,5,16,17,23,25,29]$.

Може би известен минус на R-Baux системата е, че не се отделя специално внимание на най-малките деца, където смъртният риск, подобно на най-възрастните, е повисок $[11,27]$. Други изследователи [15] посочват, че няма чак такава взаимовръзка между възрастта и смъртността при децата. Напротив, отчитат, че смъртността от изгаряне е по-малка при децата и те оцеляват дори при тежки изгаряния $[15,20,22]$.

За разлика от R-Baux, при AIS системата малката възраст се взема под внимание и еднакво по площ и степен ув- 
реждане при децата (до 5-годишна възраст) се отчита като по-тежко, с по-висок AIS показател.

Наличието при пострадалия на инхалационно увреждане също увеличава вероятността за летален изход от изгарянето $[3,4,11,14,15,20]$. Много изследователи са докладвали за връзката между инхалационните увреждания и по-високите нива̀ на смъртност [1, 9, 11, 22, 23, 25].

Нашето проучване отново доказа, че при наличие на инхалационно увреждане може да се стигне до по-тежко протичане на термичната болест и фатален изход дори при по-малко по площ и по степен изгаряне.

При изчисляване на R-Baux показателя при всички случаи с изгаряне се установи съществена разлика в средните стойности на R-Baux при оцелели и при починали $-47,8$ и 121,8 , както и рязко нарастване на броя на летално завършилите случаи при R-Baux над 110 и над 120, съответно до почти 50 и 90\%. При стойности $\geq 130$ смъртността вече е над $90 \%$, а стойности $\geq 150$ са абсолютно летални. Подобни са резултатите на Karimi и съавт. [11], които сочат 50\% смъртност при Baux 70-80, около 80\% при Baux 80-100, а при стойности, равни и по-големи от 100 - оцеляването е невъзможно. Други изследователи като Dahal и съавт. [6] отчитат при Ваuх показател 60 - смъртност повече от 50\%, а според William и Walker [30] такъв процент смъртност се наблюдава при Baux >95. При Dokter и съавт. [8] средните резултатите ca Baux 33.5 (от 12 до 56) - за пациентите, преживели термичната травма и 108 /от 91 до 127/ за починалите.

След изчисляване на AIS показателя на същите случаи с увреждане от изгаряне се установи съществена разлика в средните стойности на този показател при оцелели и при починали - 1.44 срещу 4.6. Ясно се отдиференцират и три групи според рязко нарастване броя на летално завършилите случаи: до $0.1 \%$, до $15 \%$ и над $60 \%$.

Установяват се отделни леки разминавания между прогностичната опасност за живота, определена по съответните цифрови стойности на двете системи и отчетената в медицинските документи реална смъртност. При Ваuх те са при по-ниските стойности, съответни на по-леките изгаряния, а при AIS обратно, при по-тежките изгаряния. Въпреки тях смятаме, че и двете системи са с достатъчна точност и специфичност за прогнозиране на тежестта на термичната травма и риска от смъртен изход при нея. Това е в съответствие и с посоченото от други изследователи $[1,6,8,14,18,19$, 30].

Bce пак трябва да подчертаем, че при R-Baux не се отчита най-малката възраст. За разлика от нея, при AIS децата до 5-годишна възраст се разглеждат отделно и изготвената по нея прогноза за риск от летален изход при тези случаи е малко по-точна.

Резултатите от проучването дават възможност да се оформят три групи според стойността на AIS и реализираната опасност за живота, т.е. отчетен в клиниката процент настыпил летален изход. При стойности на AIS 1 тя е под $0.1 \%$. При 2,3 и 4 е между 0.6 и 15\%, а при стойности 5 и 6 тя е между 60 и 90\%. За другата разглеждана система - R-Baux, зависимостта е: при стойности по-малки от 20 няма риск за живота, между 21 и 120 - рискът е до 44\%, а при стойности над 120 е повече от $90 \%$. Посочените резултати биха могли да служат на съдебните медици при квалифициране на телесната повреда вследствие изгаряне, според степента, в която е застрашен живота на пострадалия. (Таблица 3)

Стойностите над 150 са абсолютно летални, със 100\% отчетена реална смъртност, което дава основание да се обсъжда приемането на тези стойности не като показател за тежка телесна повреда, а за причиняване на смърт по особено мъчителен за пострадалия начин.
Таблица 3. Стойност на показателите по системите и съответния им квалификационен признак

\begin{tabular}{|cc|c|}
\hline $\begin{array}{c}\text { Cтойност } \\
\text { на AIS } \\
\text { показателя }\end{array}$ & $\begin{array}{c}\text { Cтойност } \\
\text { на R-Ваих } \\
\text { показателя }\end{array}$ & Квалификационен признак \\
\hline 1 & $\leq 20$ & $\begin{array}{l}\text { Временно разстройство на здравето, } \\
\text { неопасно за живота }\end{array}$ \\
\hline $2,3,4$ & $21-110$ & $\begin{array}{l}\text { Разстройство на здравето, временно } \\
\text { опасно за живота }\end{array}$ \\
\hline 5,6 & $>110$ & $\begin{array}{l}\text { Постоянно общо разстройство на здра- } \\
\text { вето, опасно за живота }\end{array}$ \\
\hline
\end{tabular}

\section{Изводи}

Настоящото проучване потвърждава точността на RBaux и AIS при прогнозиране на възможността за летален изход на увреждането от изгаряне. И двете системи са лесни за пресмятане, а получените резултати са достатъчно категорични при определяне на техните стойности и съответната им степен опасност за живота, а от там и квалифицирането им към конкретен медико-биологичен показател на телесна повреда. Това позволява ежедневната употреба на тези точкови системи в клиничната и съдебномедицинска практика при определяне на тежестта на увреждането от изгаряне и степента на причинената от него телесна повреда.

\section{Библиография}

1. Andel H, Kamolz LP. Scoring in burned patients our opinion. Burns 2003 , 29: $297-298$

2. Balseven-Odabasi A, Tumer A, Keten A, Yorganci K. Burn injuries among children aged up to 7 years. The Turkish J of Pediatrics. 2009;51:328-335.

3. Benito-Ruiz J, Navarro-Monzonis A, Baena-Montilla P, Mirabet-Ippolito V. An analysis of burn mortality. A report from a Spanish regional burn centre. Burns. 1991;27(3): 201-204

4. Brusselaers N, Hoste EA, Monstrey S, Colpaert KE, De Waele JJ, Vandewoude $\mathrm{KH}$, et al. Outcome and changes over time in survival following severe burns from 1985 to 2004. Intensive Care Med. 2005; 31:1648-53.

5. Brusselaers N, Monstrey S, Vogelaers D, Hoste E et al.: Severe burn injury in Europe: a systematic review of the incidence, etiology, morbidity, and mortality. Critical Care. 2010;14(5): 188.

6. Dahal P, Ghimire S, Maharjan NK, Rai SM. Baux's and Abbreviated Burn Severity Score for the Prediction of Mortality in Patients with Acute Burn Injury. JCMS Nepal. 2015;11(4): 24-27.

7. Davoodi P, Fernandez JM, O. SJ. Postburn sequelae in the pediatric patient: clinical presentations and treatment options. J Craniofac Surg. 2008; 19(4):1047-52

8. Dokter J, Meijs J, Oen IMMH, van Baar ME, van der Vlies CH, Han Boxma $\mathrm{H}$. External validation of the revised Baux score for the prediction of mortality in patients with acute burn injury. J Trauma Acute Care Surg. 2014;76(3):840-5.

9. Fujioka M, Tasaki I, Isihara Hiroshi M, Houbara S, Sasaki E. A case of severe smoke inhalation injury without cutaneous burn required massive fluid for resuscitation. Burns. 2007;11: 670-1.

10. Gennarelli TA. Abbreviated Injury Scale 2005. Update 2008. Association for the Advancement of Automotive Medicine. 2008.

11. Karimi H, MD; Motevalian SA, MD; Rabbani A, MD; Motabar AR, MD; Vasigh M, MD; Sabzeparvar M, MD; Mobayen M, MD. Prediction of Mortality in Pediatric Burn Injuries: R-Baux Score to Be Applied in Children (Pediatrics-Baux Score). Iran J Pediatr. 2013;23(2):165-170

12. Kemp AM, Jones S, Lawson Z, Maguire SA. Patterns of burns and scalds in children. Arch Dis Child. 2014; 99:316-321.

13. Klein MB, Lezotte DC, Heltshe S, et al. Functional and psychosocial outcomes of older adults after burn injury: results from a multicenter database of severe burn injury. J Burn Care Res. 2011;32(1):66-78

14. Lionelli GT, Pickus EJ, Beckum OK, DeCoursey RL, Korentager RA. A three decade analysis of factors affecting burn mortality in the elderly. Burns. 2005;31:958-963.

15. Lundgren RS, Kramer CB, Rivara FP, et al. Influence of comorbidities and age on outcome following burn injury in older adults. J Burn Care Res. 2009;30(2):307-14.

16. McGill V, Kowal-Vern A, Gamelli RL. Outcome for older burn patients. Arch Surg. 2000;135: 320-5.

17. Moore EC, Pilcher DV, Bailey MJ, et al. The Burns Evaluation and Mortality Study (BEAMS): predicting deaths in Australian and New Zealand burn patients admitted to intensive care with burns. J Trauma Acute Care Surg. 2013;75(2):298-303 
18. Olaitan PB, Jiburum BC. Analysis of burn mortality in a burns centre. Ann Burns Fire. Disasters 2006;19(2):59-62. PMID:21991024; PMCID: PMC3188036.

19. Osler T, Glance LG, Hosmer DW. Simplified estimates of the probability of death after burn injuries: extending and updating the Baux score. J Trauma. 2010;68(3):690-7

20. Roberts G, Lloyd M, Parker M, et al. The Baux score is dead. Long live the Baux score: a 27-year retrospective cohort study of mortality at a regional burns service. J Trauma Acute Care Surg. 2012;72(1):251-6.

21. Rosario Aldana MC del, Navarrete N. Epidemiology of a decade of pediatric fatal burns in Colombia, South America. Burns. 2015;41:15871592.

22. Rose JK, Herndon DN. Advances in the treatment of burn patients. Burns 1997;23(1): 19-26.

23. Ryan CM, Schoenfeld DA, Thorpe WP, Sheridan RL, Cassem EH, Tompkins RG. Objective estimates of the probability of death from burn injuries N Engl J Med. 1998;338(6):362-6.

24. Saffle JR, Davis B, Williams P. Recent outcomes in the treatment of burn injury in the United States: a report from the American burn association patient registry. J Burn Care Rehabil. 1995;16,3(1):219-32.
25. Siemers F, Liodaki E, Mauss KL, Stang FH, Wild T von, Mailaender P. Burn Injuries in Elderly - A Retrospective Analysis of a Ten Year Period. Modern Plastic Surgery. 2012;2:13-19.25.

26. Tahir SM, FCPS; Memon AR, MCPS, MS; Kumar M, FCPS; Ali SA FCPS. Prediction of Mortality After Major Burn: Physiological Versus Biochemical Measures. Wounds. 2009;2(7):1 77-182

27. Thombs BD, Singh VA, Milner SM. Children under 4 years are at greater risk of mortality following acute burn injury: evidence from a national sample of 12,902 pediatric admissions. Shock. 2006; 26(4):348-52.

28. Tompkins RG, Burke JF, Schoenfeld DA, et al. Prompt eschar excision: a treatment system contributing to reduced burn mortality: a statistical evaluation of burn care at the Massachusetts General Hospital (1974-1984). Ann Surg. 1986; 204:272-81.

29. Wibbenmeyer LA, Amelon MJ, Morgan LJ, Robinson BK, Chang PX, Lewis II R, et al. Predicting survival in an elderly burn patient population. Burns. 2001;27:583-90.

30. Williams DJ, Walker JD. A nomogram for calculation of the Revised Baux Score. Burns. 2015; 41(1):85-90

31. Zawacki BE, Azen SP, Imbus SH, Chang YT. Multifactorial probit analysis of mortality in burned patients. Ann Surg. 1979;189(1):1-5.

\title{
ХАРАКТЕРИСТИКИ НА ИЗГАРЯНИЯТА В ДЕТСКА ВЪЗРАСТ
}

\author{
Е. Каитева, Д. Радойнова, Й. Заякова
}

\section{CHARACTERISTICS OF THERMAL INJURIES IN CHILDREN}

\author{
E. Kaisheva, D. Radoinova, J. Zaiakova
}

\begin{abstract}
Рез юме. Проучването има за ичел да се определянят факторите от страна на причиняващия агент, на пострадалия организъм и на околната среда от значение за развитието на термичната болест при деца, с иел превенция на тези тежки, а понякога и с фатален изход случаи. За проучването са използвани данни от историите на заболяване на пациенти до 18-годишна възраст, постъпили за лечение в КТТПВЕХ при „МБАЛ-Варна”, за 5-годишен период (20112015 г.). За този период в клиниката са лекувани 565 деца с термична травма, от които 221 момичета (39.1\%) и 344 момчета (60.9\%). Два от случаите са с летален изход. Изгарянията са най-чести във възрастовата група 1-5 г. - 367 (65\%), като повече от 60\% от тях са момчета. Най-често това са попарвания с гореща вода или друга течност - 373 (66,3\%) случаи, в много по-малко случаи изгарянето е контактно или пламъково, съответно 109 (19,4\%) и 55 (9,85\%). При повече от три четвърти от случаите изгарянето обхваща под $10 \%$ от общата телесна повърхност. Получените резултати могат да спомогнат за разработване на програма, целяща намаляването на тези тежки от медицинска, съдебномедиииска, сочиална и икономическа гледна точка случаи.
\end{abstract}

$\boldsymbol{S}$ u $\boldsymbol{m} \boldsymbol{m}$ a ry. The purpose of our study was to identify and determine the characteristics of the factors that are significant for the development of thermal injuries in children: the causing agent, the suffering organism, the environment; in order to prevent these severe and sometimes fatal cases. We used data from patients' histories (aged < 18 years) admitted to the Clinic of Thermal Traumas and Plastic-Restorative and Aesthetic Surgery at the Military Hospital-Varna for a 5 years period (2011-2015). During this period, 565 children with thermal injuries were treated in the clinic (221 girls $/ 39.1 \%$ and 344 boys $/ 60.9 \%)$. Two of the cases had a fatal outcome. The most common cases included hot water or other liquid burns (367/65\%); there were far less cases of contact or flame burns: 109 (19.4\%) and 55 (9.85\%). In more than three quarters of the cases, the burns affected less than 10\% of the total body surface area. It is advisable to analyse the obtained results in order to help develop a program aimed at reducing the severity of these cases from a medical, forensic, social and economic point of view.

Key words: thermal injury, children, thermal factors

\section{Въведение}

Половината от случаите с изгаряне, постьпили в болниците в Европа, са деца $[6,8,15]$. Тези травми са с голямо медицинско, социално и икономическо значение, тъй като дават отражение върху живота на пострадалия, на неговото семейство и на обществото като цяло. При термичната травма е възможно настъпване на летален изход както веднага след получаване на изгарянето, така и на по-късен етап в хода на развитието на термичната болест. Уврежданията са съпроводени със силна болка, деформация и нарушена функция на засегнатата телесна област, обезобразяване, инвалидизиране и налагат скъпоструващи, специализирани медицински грижи и лечение за продължителен период от време [3, 4, $8,15,18,22]$. Проучвания в САЩ и Израел са отчели, че изгарянията са третата по честота причина за смърт сред децата $[20,22]$. Тежестта им, показателите на развилата се термична болест, продължителността на болничното лечение и сроковете за възстановяване зависят от редица фактори като: биомедицински характеристики на пострадалото дете, вид на действалия термичен агент, място на контакт (особености на самата засегната телесна област), механизъм на получаване на увреждането, условия, при които то е получено и продължителност на периода между инцидента и започването на специализирано лечение [15, 16, 29]. 